\title{
A retrospective analysis of bone mineral status in patients requiring spinal surgery
}

Tobias Schmidt ${ }^{1,2^{*}+}$ (D), Katharina Ebert ${ }^{1 \dagger}$, Tim Rolvien ${ }^{1,2}$, Nicola Oehler ${ }^{2}$, Jens Lohmann ${ }^{3}$, Luca Papavero ${ }^{3}$, Ralph Kothe ${ }^{3}$, Michael Amling ${ }^{1}$, Florian Barvencik ${ }^{1}$ and Haider Mussawy ${ }^{1,2}$

\begin{abstract}
Background: Impaired bone quality is associated with poor outcome of spinal surgery. The aim of the study was to assess the bone mineral status of patients scheduled to undergo spinal surgery and to report frequencies of bone mineral disorders.

Methods: We retrospectively analyzed the bone mineral status of 144 patients requiring spinal surgery including bone mineral density by dual-energy X-ray absorptiometry (DXA) as well as laboratory data with serum levels of 25-hydroxyvitamin D (25-OH-D), parathyroid hormone, calcium, bone specific alkaline phosphate, osteocalcin, and gastrin. High-resolution peripheral quantitative computed tomography (HR-pQCT) was additionally performed in a subgroup of 67 patients with T-Score below -1.5 or history of vertebral fracture.

Results: Among 144 patients, 126 patients (87.5\%) were older than 60 years. Mean age was 70.1 years. 42 patients (29.1\%) had suffered from a vertebral compression fracture. 12 previously undiagnosed vertebral deformities were detected in 12 patients by vertebral fracture assessment (VFA). Osteoporosis was present in 39 patients (27.1\%) and osteopenia in 63 patients (43.8\%). Only 16 patients (11.1\%) had received anti-osteoporotic therapy, while 54 patients (37.5\%) had an indication for specific anti-osteoporotic therapy but had not received it yet. The majority of patients had inadequate vitamin D status (73.6\%) and $34.7 \%$ of patients showed secondary hyperparathyroidism as a sign for a significant disturbed calcium homeostasis. In a subgroup of 67 patients, severe vertebral deformities were associated with stronger deficits in bone microarchitecture at the distal radius compared to the distal tibia.

Conclusions: This study shows that bone metabolism disorders are highly prevalent in elderly patients scheduled for spinal surgery. Vertebral deformities are associated with a predominant deterioration of bone microstructure at the distal radius. As impaired bone quality can compromise surgical outcome, we strongly recommend an evaluation of bone mineral status prior to operation and anti-osteoporotic therapy if necessary.
\end{abstract}

Keywords: Osteoporosis, Vitamin D deficiency, Secondary hyperparathyroidism, Hypochlorhydria, Anti-osteoporotic medication

\section{Background}

Osteoporosis is a progressive disease that is characterized by a decrease in bone mass density and structures changes in trabecular and cortical bone leading to an increased risk of fractures. It is estimated that over 200 million people worldwide suffer from osteoporosis [1].

\footnotetext{
* Correspondence: to.schmidt@uke.de

${ }^{\dagger}$ Equal contributors

${ }^{1}$ Department of Osteology and Biomechanics, University Medical Center Hamburg-Eppendorf, Lottestraße 59, 22529 Hamburg, Germany ${ }^{2}$ Department of Orthopedic Surgery, University Medical Center Hamburg-Eppendorf, Martinistrasse 52, 20246 Hamburg, Germany Full list of author information is available at the end of the article
}

Moreover, it has been predicted that the lifetime risk of osteoporotic fractures in the United States is approximately $30-50 \%$ in women and $15-30 \%$ in men and that more than $40 \%$ of postmenopausal women will suffer one or more fragility fractures in their remaining lifetime [2].

Vertebral compression fractures are the most common complication of osteoporosis and strongly affect patients' overall health. The presence of a vertebral fracture increases the risk of a new vertebral fracture by five-fold [3] and patients with vertebral fractures often suffer from severe pain that can lead to long-term care and hospitalization which is associated with further 
complications [4]. Furthermore, patients with vertebral fractures are at much greater risk for developing changes in spine structure as kyphotic deformities and spinal stenosis due to sagittal imbalance and degenerative changes [5].

Osteoporosis can be diagnosed by low bone density measured by dual-energy X-ray absorptiometry (DXA) or by a fragility fracture. Although DXA is the gold standard to measure areal bone mineral density (aBMD), it cannot be used to gain insights into three-dimensional bone architecture changes or distinguish between the cortical and trabecular compartments. In addition, it is well known that fractures often occur in patients with a T-score above 2.5, who therefore do not meet the World Health Organization (WHO) criteria of osteoporosis [6]. These limitations of DXA are important because patients with vertebral fractures not only often have degenerative bone changes that influence the correct interpretation of the lumbar BMD, but in such cases DXA-measured aBMD at the lumbar spine may yield false high values.

In patients with vertebral fractures, the vertebral bodies are characterized by reduced bone volume tissue and the loss of trabeculae [7]. Interestingly, similar deficits are also observed in peripheral bone $[8,9]$. This could explain why these patients are at particular risk of vertebral and peripheral fractures in the future $[10,11]$. It also suggests that one way to improve the diagnosis of vertebral fractures is by assessing the peripheral bone architecture via highresolution peripheral quantitative computed tomography (HR-pQCT) [12]. Indeed, several studies show that HRpQCT measurements of the peripheral bone microstructure are predictive of osteoporosis-related fractures [13, 14].

In the recent years there have been significant advances in the management of osteoporosis. Many studies have investigated the effect of vitamin $\mathrm{D}$ and calcium supplements on osteoporosis and fracture risk [15]. Low circulating levels of 25-hydroxyvitamin D (25-OH-D) may lead to increased secretion of parathyroid hormone $(\mathrm{PTH})$ which in turn induces bone loss through increased bone resorption. Despite the importance of vitamin D for maintaining balanced calcium homeostasis, deficiency is highly prevalent in Europe population particularly in northern Europe countries like Germany, where in contrast to Scandinavia food fortification with vitamin $\mathrm{D}$ is still lacking $[16,17]$.

In this study, we collected data of bone mineral status and bone quality in patients scheduled for spine surgery and report rates of untreated osteoporosis, vitamin D deficiency and hyperparathyroidism in a patient cohort in northern Germany.

\section{Methods}

\section{Study group}

Since early 2015 to the end of 2016 a total of 144 consecutive adult patients ( $>50$ years of age), who were scheduled for spine surgery in a single center in north Germany, were examined at our institution and included in this retrospective cross-sectional study. All patients were interviewed for previous fractures, medical treatment including anti-osteoporotic treatment and vitamin D supplementation, and associated diseases. Patients with diabetes mellitus type 1 , treatment with glucocorticoids lasting over 3 months or tumors were excluded. Patients whose vertebral fractures were the result of major trauma were also excluded. Indication for specific anti-osteoporotic treatment was determined by using the evidence-based (S3) guidelines of German Association of Osteology (DVO). This guideline currently recommends the use of denosumab, raloxifene, bazedoxifene, estrogens, alendronate, risedronate, ibandronate, zoledronic acid, teriparatide and strontium ranelate as specific anti-osteoporotic treatment medication. Informed consent was obtained from all patients for the retrospective and anonymized database studies. This study was performed in accordance with the Declaration of Helsinki. The local ethics committee of the University Medical Center Hamburg-Eppendorf approved this retrospective study (PV5271).

\section{Dual-energy X-ray absorptiometry (DXA)}

All patients underwent aBMD measurements by DXA (iDXA, GE Healthcare, UK). Three skeletal areas, the both proximal femur and the lumbar spine (L1-L4), were measured by DXA. The patients were placed in the supine position and scanned according to the manual supplied by the manufacturer. The detected aBMD of the projected bone area was expressed in grams per square centimeter $(\mathrm{g} / \mathrm{cm} 2)$, and the corresponding T-, and Z-Score was calculated using the reference database provided by the manufacturer. DXA measurement at lumbar spine had to be excluded due to degenerative osteoproliferative changes in 25 patients and DXA measurement at proximal femur was not possible due to bilateral hip replacement in 13 patients. Yet, all patient in this study had at least one representative DXA measurement. The vertebral fractures were confirmed with vertebral fracture assessment (VFA) by DXA (Fig. 1a-c). Vertebral deformity severity was measured using VFA by DXA followed by grading of the vertebrae according to the semiquantitative method of Genant. Moderate deformity was defined as reduction of $25-40 \%$ in anterior, middle, and/or posterior vertebral height, while severe deformity was defined as a reduction in any of these heights by more than $40 \%$ [18].

\section{High-resolution peripheral quantitative computed tomography (HR-pQCT)}

The patients $(n=67)$ with a T-score below -1.5 or a history of a vertebral fracture received additional assessment of peripheral bone structure by HR-pQCT (XtremeCT ${ }^{\circ}$, Scanco Medical AG, Brüttisellen). HR-pQCT scans of the 

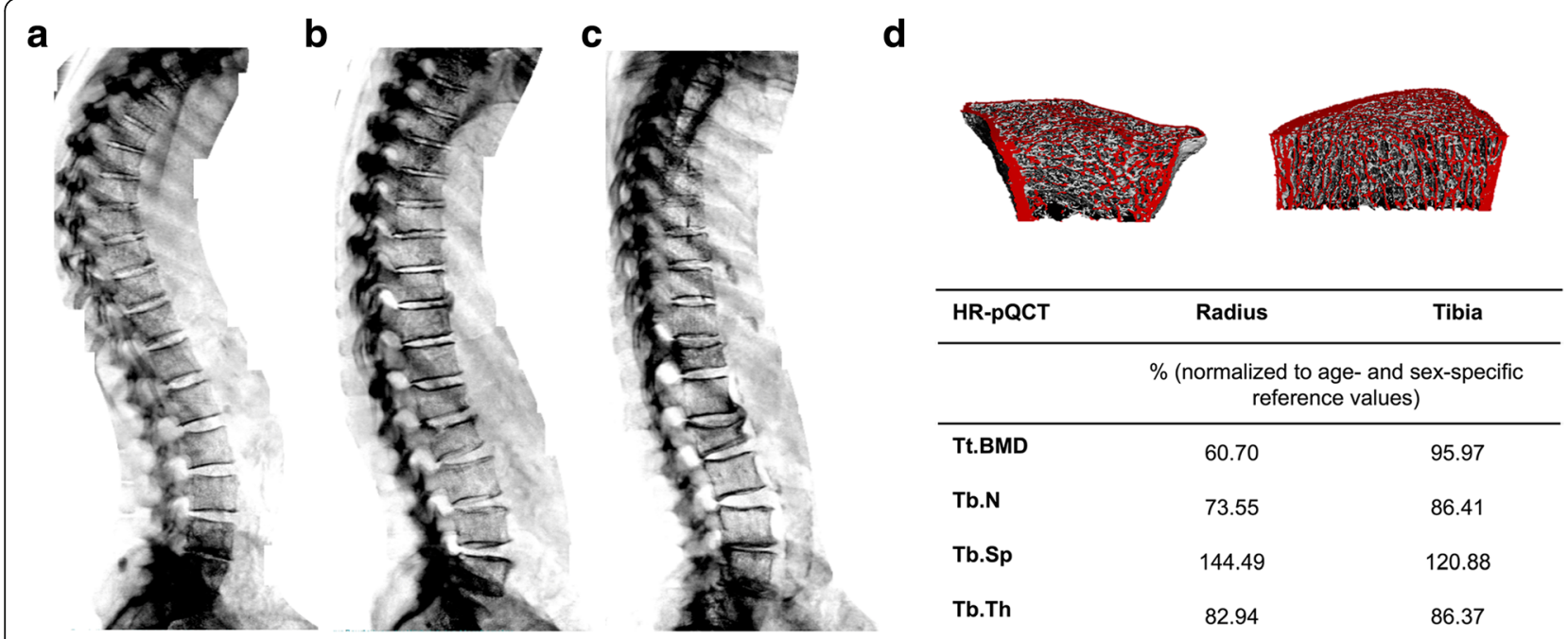

Fig. 1 a Sample images of lateral vertebral fracture assessment by DXA in patients without vertebral fracture; $\mathbf{b}$ with moderate deformity of the first and second lumbar vertebrae; c and with severe deformity of the second lumbar vertebra and moderate deformity of the twelfth thoracic vertebra. $\mathbf{d}$ Sample image of the peripheral quantitative computed tomographic analysis of the distal radius and distal tibia of a patient with severe vertebral deformity. Note that the same patient exhibits a strong decrease in the trabecular compartment at the distal radius and a less pronounced decrease in trabecular variables at the distal tibia. Values are normalized to age-, site-, and sex-specific reference values. Abbreviations: HR-pQCT, peripheral quantitative computed tomography; Tt.BMD, total volumetric bone mineral density. Tb.N; trabecular numbers Tb.Sp; trabecular separation Tb.Th; trabecular thickness

non-dominant distal radius (in cases of previous fracture, the contralateral limb was scanned) and the distal tibia were analyzed. The measured region was manually defined by a trained operator by placing a reference line at the endplate of the radius and tibia on a preliminary performed scout view. The same operator generated semiautomatic contours around the periosteal surface and the entire volume of interest is thereafter automatically separated into a cortical and trabecular region. A quality scan for calibration of the CT system was performed each day by using a phantom provided by the manufacturer. The scanning settings used were $60 \mathrm{kV} / 40 \mathrm{keV}$ at a current of $900 \mu \mathrm{A}$. Each image comprised 110 slices with an isotropic voxel size of $82 \mu \mathrm{m}$. The following variables were analyzed by using the HR-pQCT system: total, cortical and trabecular area, total, cortical and trabecular volumetric $\mathrm{BMD}$, cortical thickness, trabecular number, trabecular thickness, and trabecular separation. HR-pQCT values were normalized to age-, site-, and sex-specific reference values [19] and are expressed as percentage of corresponding reference value.

\section{Laboratory values}

Biochemical analyses of bone metabolism markers including serum levels of alkaline phosphatase (ALP), bone specific alkaline phosphatase (BAP), 25-OH-D, calcium, parathyroid hormone (PTH) and urinary level of deoxypyridinoline (DPD) were assessed by routine lab tests for evaluating osteoporosis. Reference values were adapted from the local laboratory for each parameter. Vitamin D inadequacy was defined as a 25-OH-D level below $30 \mathrm{ng} / \mathrm{ml}$ and deficiency as levels less than $20 \mathrm{ng} / \mathrm{ml}$. These values reflect those of widely accepted thresholds [20]. Calcium, gastrin, 25-OH-D and parathyroid hormone were measured in all patients, bone specific AP were only measured in 115 patients, osteocalcin in 111 patients and urinary levels of DPD in 107 patient.

\section{Statistics}

The IBM SPSS statistics 22 program was used for statistical analyses. Data are expressed as mean values \pm SD. Normal distribution of the data was tested with the KolmogorovSmirnov test. To test the differences between the study groups, we used the unpaired two-sided t-test and one-way ANOVA and post hoc Bonferroni test on the normally distributed data and the Mann-Whitney U test and Kruskal Wallis test for non-normally distributed data. $P$ values of $<0.05$ were considered as statistically significant.

\section{Results}

\section{Study population characteristics}

A total of 144 consecutive adult patients older than 50 years were included in this retrospective study. All patients were scheduled for spine surgery. The mean age and BMI was $70.1 \pm 8.1$ years and $26.2 \pm 4.87 \mathrm{~kg} / \mathrm{m}^{2}$, respectively. Among 144 patients, 96 (66.4\%) were females. 42 patients had suffered from a vertebral compression fracture in the past. Almost half of the patients (48.6\%) had a diagnosis of lumbar spinal stenosis. Table 1 summarizes the characteristics of the study population. 
Table 1 Demographic and laboratory data of of patients requiring spinal surgery

\begin{tabular}{|c|c|}
\hline & Mean $( \pm \mathrm{SD})$ or $\mathrm{n}(\%)$ \\
\hline$n$ & 144 \\
\hline Sex (no. of female, \%) & $96(66.4)$ \\
\hline Mean age in yr & $70.1(8.1)$ \\
\hline \multicolumn{2}{|l|}{ Age (no. of patients) } \\
\hline $50-60 \mathrm{yr}$ & $18(12.5 \%)$ \\
\hline $60-70$ yr & $55(38.2 \%)$ \\
\hline$>70 \mathrm{yr}$ & $71(49.3 \%)$ \\
\hline Weight (kg) & $74.8(14.4)$ \\
\hline Height (cm) & $168.0(9.4)$ \\
\hline Height change (cm) & $3.7(2.9)$ \\
\hline Mean BMI ( \pm SD) & $26.2(4.7)$ \\
\hline History of a vertebral fracture & $42(29.1 \%)$ \\
\hline $\begin{array}{l}\text { Unknown vertebral deformity } \\
\text { (Diagnosed by VFA) }\end{array}$ & $12(8.3 \%)$ \\
\hline Proton pump inhibitor use & $44(30.6 \%)$ \\
\hline \multicolumn{2}{|l|}{ Laboratory values } \\
\hline $25-\mathrm{OH}-\mathrm{D}(\mathrm{ng} / \mathrm{ml})$ & $24.3(11.8)$ \\
\hline Parathyroid hormone (ng/l) & $84.3(47.1)$ \\
\hline Calcium (mmol/l) & $2.23(0.1)$ \\
\hline Bone specific AP $(\mu \mathrm{g} / \mathrm{l})(n=115)$ & $13.6(7.9)$ \\
\hline Osteocalcin $(\mu \mathrm{g} / \mathrm{l})(n=111)$ & $18.9(11.8)$ \\
\hline Urine DPD $(n=107)$ & $6.7(2.8)$ \\
\hline Elevated DPD & $74(69.2 \%)$ \\
\hline Elevated Gastrin & 20 (13.9\%) \\
\hline
\end{tabular}

\section{Bone densitometry}

DXA was performed in all patients. However, DXA measurement in 25 patients at lumbar spine had to be excluded due to degenerative osteoproliferative changes. In 13 patients DXA measurement at the proximal femur was not possible due to bilateral hip replacement. Yet, all patient in this study had at least one representative DXA measurement. Osteoporosis at the lumbar spine was diagnosed in 27 of 119 patient $(22.7 \%)$ whereas 22 of 131 patients (16.8\%) showed T-scores below -2.5 at the femur. Incidence of osteopenia was $34.5 \%$ at the lumbar spine and $45.8 \%$ at the femur. Table 2 shows the indication for spinal surgery and the corresponding Tand Z-scores for each subgroup. Patients requiring spinal surgery due to a compression fracture showed the lowest $\mathrm{T}$ - and Z-scores at the lumbar spine and at the femoral neck.

\section{Deterioration of bone structure at the distal radius is associated with severity of vertebral fracture}

Vertebral fracture assessment (VFA) of the spine revealed 12 previously unknown vertebral deformities in 12 different patients. Fig. 1a-c shows sample images of VFA by DXA in patients without vertebral deformity (a), moderate deformity (b) and severe deformity (c). In a subgroup of 67 patients with a T-score below -1.5 or a history of fracture, we used HR-pQCT for further assessment of bone microstructure at the distal radius and distal tibia. 21 and 12 patients of this subgroup had moderate and severe vertebral fractures, respectively. The patients did not differ significantly in terms of age (mean 71.9 vs. 71.6), weight $(72.7 \mathrm{~kg}$ vs. $78.4 \mathrm{~kg})$, height $(166 \mathrm{~cm}$ vs. $170 \mathrm{~cm})$, or BMI (26.1 vs 26.9). Interestingly, when we compared patients with vertebral deformities to patients without deformities, the cases with severe vertebral deformity had significantly lower total volumetric BMD (17.75\%) as well as trabecular and cortical microstructure parameters at the distal radius (Table 3). The tibial values demonstrated similar trends, albeit less pronounced and without achieving statistical significance (Table 3). Figure 1d demonstrates images of a patient with pronounced deterioration of bone microstructure at the distal radius.

\section{Vitamin D status}

25-OH-D and PTH were measured in all patients. Vitamin $\mathrm{D}$ inadequacy was defined as a 25-OH-D level below $30 \mathrm{ng} / \mathrm{ml}$ and deficiency as levels less than $20 \mathrm{ng} / \mathrm{ml}$. The mean 25-OH-D concentration was $24.3 \mathrm{ng} / \mathrm{ml}$. Values ranged from 4 to $60 \mathrm{ng} / \mathrm{ml}$. The overall prevalence of vitamin $\mathrm{D}$ inadequacy was $73.6 \%$ and that of deficiency was $36.8 \%$ (Fig. 2a). Severe deficiency $(25-\mathrm{OH}-\mathrm{D}<10 \mathrm{ng} / \mathrm{ml})$ was present in 17 patients (11.6\%). 50 (35.4\%) patients showed elevated PTH levels. While 12 of these patients showed hypocalcemic hyperparathyroidism, 38 patients displayed elevated PTH levels with normocalcemia. One patient showed elevated calcium and PTH levels

Table 2 T-scores and Z-scores of the DXA measurements in patients with different indication for spinal surgery (mean \pm SD)

\begin{tabular}{llllll}
\hline & $\mathrm{n}$ & T-Score lumbar spine & Z-Score lumbar spine & T-Score femoral neck & Z-Score femoral neck \\
\hline $\begin{array}{l}\text { All patients } \\
\text { Indication for spinal surgery }\end{array}$ & 144 & $-1.23(1.4)$ & $-0.1(1.5)$ & $-1.4(1.0)$ & $-0.08(1.1)$ \\
$\quad$ Lumbar spinal stenosis & 70 & $-1.29(1.73)$ & $0.07(1.56)$ & $-1.62(1.15)$ & $-0.04(1.08)$ \\
$\quad$ Degenerative spondylolisthesis & 35 & $-1.14(1.45)$ & $-0.20(1.38)$ & $-1.16(0.98)$ & $0.12(1.10)$ \\
$\quad$ Herniation of lumbar disc & 31 & $-0.77(1.21)$ & $-0.04(1.41)$ & $-1.06(0.88)$ & $0.32(1.38)$ \\
$\quad$ Compression fracture & 8 & $-2.6(1.3)$ & $-1.27(0.91)$ & $-1.72(1.07)$ & $-0.13(1.05)$ \\
\hline
\end{tabular}


Table 3 Differences in bone microarchitecture between the patients with moderate/severe vertebral deformity and the patients without vertebral fractures

\begin{tabular}{|c|c|c|c|c|c|}
\hline & No Deformity & Moderate Deformity & & Severe Deformity & \\
\hline $\mathrm{n}$ & 34 & 21 & & 12 & \\
\hline Mean age, years & 71 & 71.9 & & 72 & \\
\hline \multicolumn{6}{|l|}{ HR-pQCT variables } \\
\hline Radius (normalized to age- and sex-specific reference values) & $\%$ & $\%$ & $\Delta \%$ & $\%$ & $\Delta \%$ \\
\hline Total bone area & $109.8(15.7)$ & $113.4(18.5)$ & +3.5 & $110.2(30.7)$ & +0.35 \\
\hline Cortical area & $88.8(21.7)$ & $78.3(27.3)$ & -10.5 & $65.4(19.5)$ & $-23.4^{*}$ \\
\hline Trabecular area & $110.8(20.4)$ & $117.2(24.4)$ & +6.2 & $116.7(36.8)$ & +5.7 \\
\hline Total vBMD & $94.9(20.7)$ & $87.2(18.9)$ & -7.6 & $76.2(12.5)$ & $-18.7^{*}$ \\
\hline Cortical vBMD & $83.3(7.0)$ & $80.1(8.4)$ & -3.1 & $77.7(6.9)$ & -5.5 \\
\hline Trabecular vBMD & $100.7(20.7)$ & $93.5(25.7)$ & -7.3 & $79.7(17.4)$ & $-21.0^{*}$ \\
\hline Cortical thickness & 70.4 (18.9) & $61.1(24.4)$ & -9.4 & $50.8(14.9)$ & $-19.6^{*}$ \\
\hline Trabecular numbers & $106.8(14.6)$ & $102.4(22.7)$ & -4.4 & $92.4(16.9)$ & $-14.4^{*}$ \\
\hline Trabecular thickness & $94.9(13.1)$ & $92.0(17.3)$ & -2.8 & $87.1(13.5)$ & $-7.8^{*}$ \\
\hline Trabecular separation & $95.8(15.8)$ & $105.3(32.2)$ & +9.5 & $116.8(28.1)$ & $+20.9^{*}$ \\
\hline Tibia (normalized to age- and sex-specific reference values) & $\%$ & $\%$ & $\Delta \%$ & $\%$ & $\Delta \%$ \\
\hline Total bone area & $112.1(17.5)$ & $115.5(21.3)$ & +3.4 & $109.8(19.5)$ & -2.3 \\
\hline Cortical area & $90.7(15.2)$ & $91.6(18.5)$ & +0.9 & $81.7(15.7)$ & -9.0 \\
\hline Trabecular area & $98.3(15.4)$ & $99.4(22.6)$ & +1.1 & $95.6(20.7)$ & -2.6 \\
\hline Total vBMD & $90.7(15.2)$ & $91.6(18.4)$ & +0.9 & $81.7(15.7)$ & -9.0 \\
\hline Cortical vBMD & $85.8(8.8)$ & $86.4(8.9)$ & +0.6 & $82.7(7.9)$ & -3.1 \\
\hline Trabecular vBMD & 98.5 (18.9) & $98.5(23.6)$ & -0.0 & $87.8(18.2)$ & -10.6 \\
\hline Cortical thickness & $67.7(21.5)$ & $68.9(26.0)$ & +1.2 & $58.8(23.8)$ & -8.8 \\
\hline Trabecular numbers & $110.1(18.5)$ & $105.8(25.4)$ & -4.3 & $102.9(22.1)$ & -7.1 \\
\hline Trabecular thickness & $90.6(15.7)$ & $93.2(12.4)$ & +2.6 & $87.0(19.1)$ & -3.6 \\
\hline Trabecular separation & $94.1(19.6)$ & $101.5(29.6)$ & +7.4 & $104.9(28.9)$ & +10.8 \\
\hline
\end{tabular}

Abbreviations: $\mathrm{HR}-\mathrm{pQCT}$, peripheral quantitative computed tomography; $\mathrm{vBMD}$, volumetric bone mineral density

The data are normalized to age- and sex-specific reference values. The differences $(\Delta)$ that are shown are relative to the non-fracture group.

$*$ Statistically significant $(p<0.05)$ differences to the non-fracture group

and was consequently diagnosed with primary hyperparathyroidism and were treated surgically with parathyroidectomy after preoperative localization of parathyroid adenoma. 44 (30.6\%) patients used proton pump inhibitors and 20 (13.9\%) of these patient showed elevated levels of gastrin suggesting PPI induced hypochlorhydria.

\section{Anti-osteoporotic treatment}

57 patients used vitamin D supplementation. However, only 28 of these patients had 25-OH-D levels above $30 \mathrm{ng} / \mathrm{ml}$ suggesting adequate vitamin $\mathrm{D}$ supplementation (Table 4). Patients with vitamin D supplementation were divided into two groups by daily intake of vitamin D. While patients with 500-1000 I.E. of vitamin D intake per week showed mainly vitamin D inadequacy, patients with higher intake mostly showed adequate levels (Fig. 2b). However, PTH levels did not differ significantly between these groups. Patients with no vitamin
D supplementation had significantly higher level of PTH (Fig. 2b). While only 16 patients $(11.1 \%)$ were previously treated with specific anti-osteoporotic medication, 54 patients $(37.5 \%)$ had not received specific anti-osteoporotic treatment as recommended by the evidence-based (S3) guidelines of German Association of Osteology (Table 4) despite having an indication.

\section{Recommendation for anti-osteoporotic treatment}

Figure 3 summarizes the major findings and implication for anti-osteoporotic treatment in the patient cohort. Vitamin D supplementation was suggested in dependence of 25-OH-D levels. Patients with hypochlorhydria due to PPI use were recommended to use calcium gluconate supplementation to improve calcium absorption $[21,22]$. Indication for specific anti-osteoporotic treatment was established by using the current official recommendation of the German Association of Osteology. The choice 


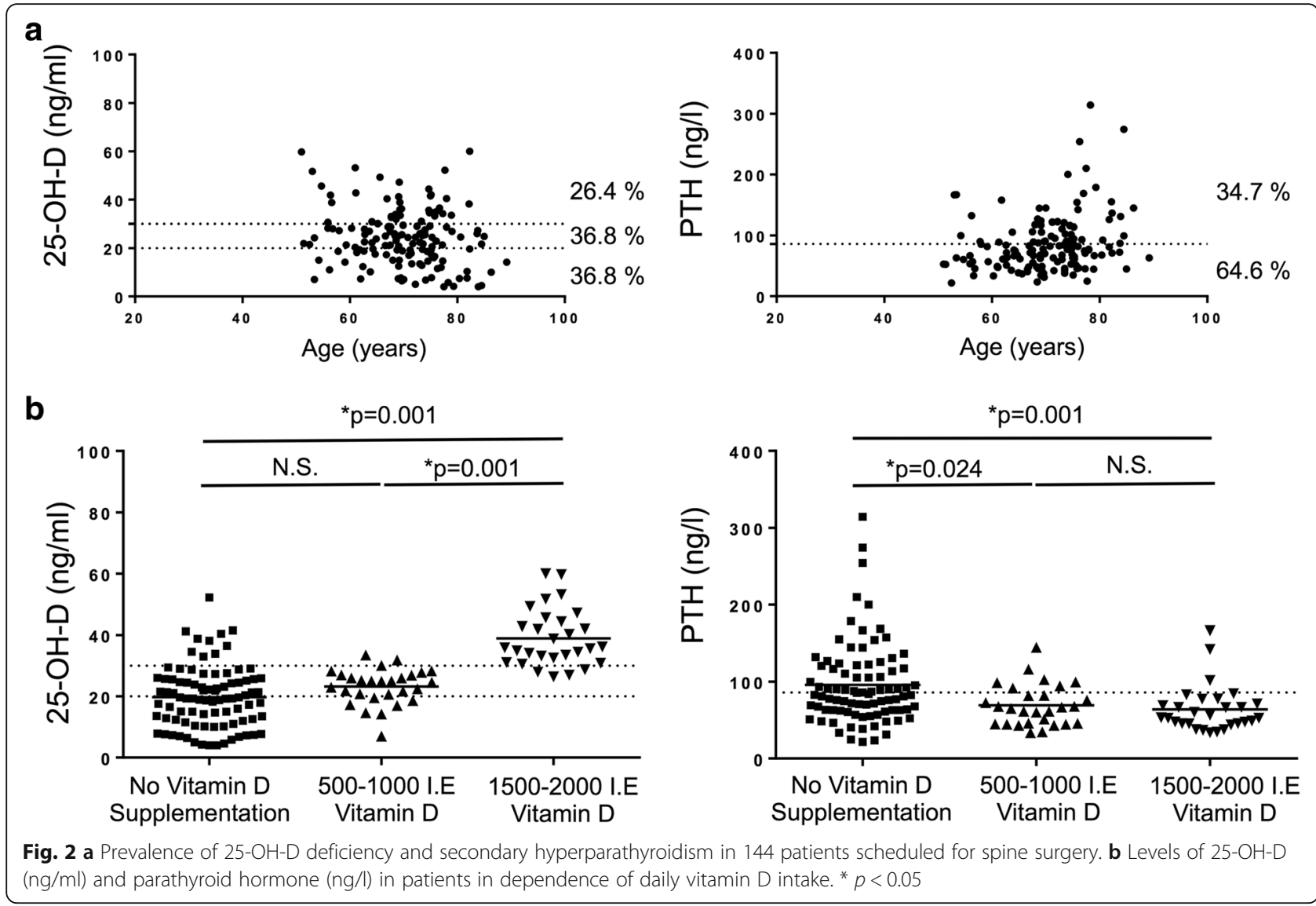

Table 4 Anti-osteoporotic treatment in patients undergoing spinal surgery prior and recommendation after evaluation of bone mineral status

\begin{tabular}{lll}
\hline & $\begin{array}{l}\text { Prior to } \\
\text { Evaluation } \\
\text { n (\%) }\end{array}$ & Recommendation \\
\hline Basic therapy & $\mathrm{n}(\%)$ \\
$\quad$ Vitamin D supplementation & $57(39.6 \%)$ & $144(100 \%)$ \\
$\begin{array}{l}\text { Adequate vitamin D } \\
\text { supplementation }\end{array}$ & $28(19.4 \%)$ & \\
$\begin{array}{l}\text { (25-OH-D within } \\
\text { recommended range) }\end{array}$ & & \\
Calcium supplementation & $31(21.5 \%)$ & $20(13.9 \%)$ \\
Specific anti-osteoporotic treatment & $16(11.1 \%)$ & $70(48.6 \%)$ \\
$\quad$ Bisphosphonate (oral) & $8(5.6 \%)$ & $26(18 \%)$ \\
Bisphosphonate (intravenous) & $0(0 \%)$ & $14(9.7 \%)$ \\
Denosumab & $8(5.6 \%)$ & $25(17.3 \%)$ \\
Teriparatide & $0(0 \%)$ & $5(3.5 \%)$ \\
Indication for specific treatment & $54(37.5 \%)$ & \\
without therapy & & \\
\hline
\end{tabular}

of medication was based on an individualized decision taking risk factors and current bone mineral status and turnover into account.

\section{Discussion}

In this study we analysed the bone health of patients requiring spinal surgery. We found a high prevalence of untreated osteoporosis, vitamin D deficiency and parathyroid hormone elevations arising from vitamin $\mathrm{D}$ deficiency.

Many studies suggest that BMD is one of the main factors related to poor surgical outcome of patients undergoing spine fusion operations with instrumentation [23]. The ability of screws to resist pullout from bone is directly related to BMD [24]. Moreover, longer fusion constructs are recommended for patients with an osteoporotic spine resulting in longer operative time and increased postoperative time to recovery [25]. Hence, assessment of bone quality prior to operation is crucial finding the optimal surgical strategy to proactively plan for best surgical outcomes.

According to World Health Organization (WHO) recommendations every postmenopausal women and patients with high number of osteoporosis risk factors should undergo bone mineral density screening [26]. Prevalence of osteopenia and osteoporosis for patients requiring spine 


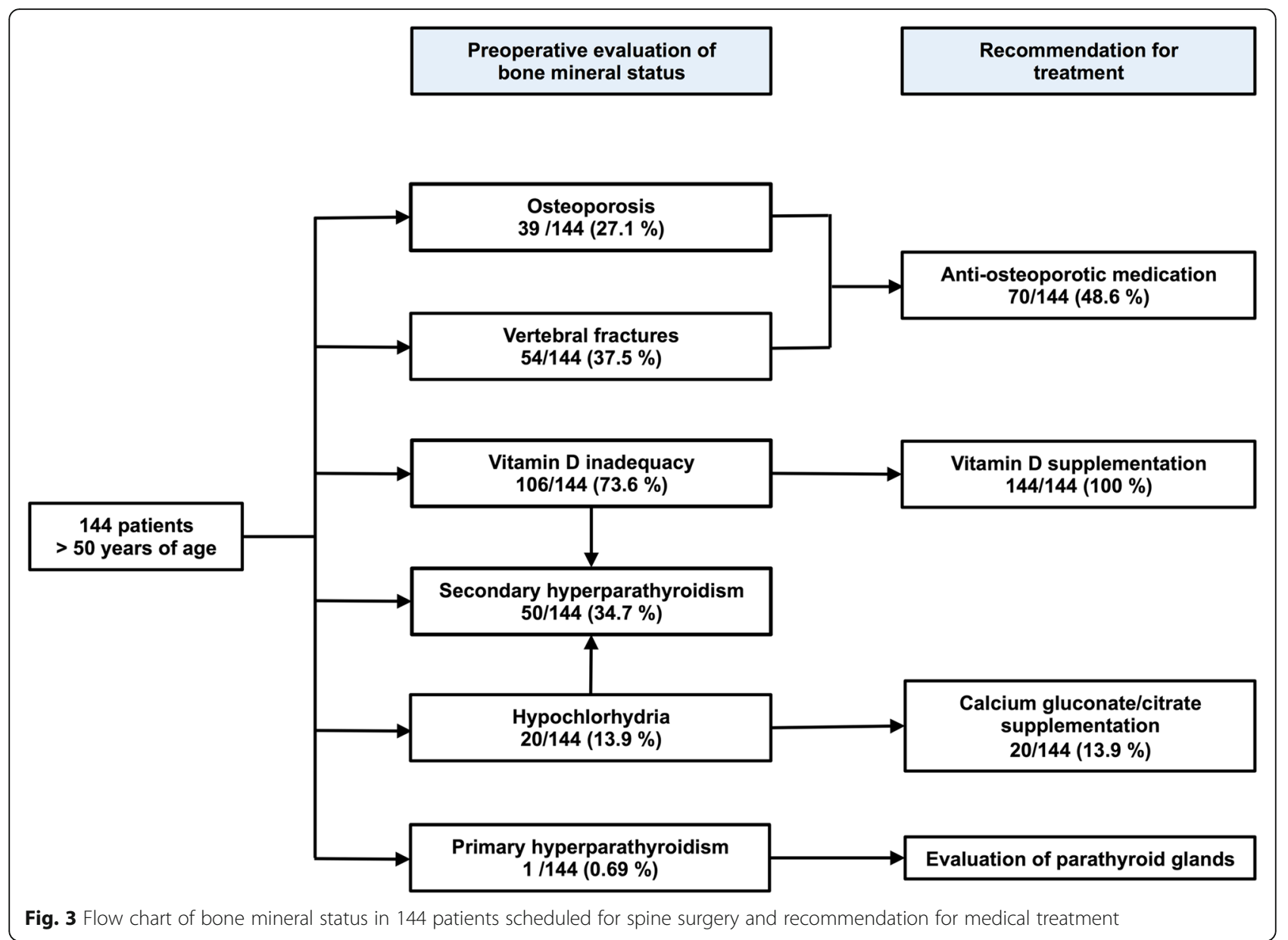

surgery have been shown to be high with $46 \%$ and $31 \%$ for patients older than 50 years [27], respectively. While DXA is the gold standard to measure aBMD, it has been frequently reported that fractures often occur in patients with a T-score above $-2.5[6]$ and that women with osteopenia and a prevalent fracture have the same fracture risk as women with osteoporosis [28]. In this context, it has been shown that other factors such as vitamin D deficiency or a predominant cortical bone loss are independently associated with increased fracture risk $[29,30]$. Hence, to prevent future fractures and to archive better surgical outcome, it is important to identify and treat patients with reduced bone quality. It would be desirable that in elderly patients (> 50 years) scheduled to undergo elective spine surgery, bone mineral status including DXA measurement and biochemical assessment for reversible risk factors should be determined routinely and appropriate medical treatment including vitamin D supplementation initiated if necessary. In patients with a previous fracture and osteopenia or $\mathrm{T}$-score within the normal range, assessment of peripheral bone structure by HR-pQCT can give useful additional information about the bone quality.
In this study, we found that patients with vertebral deformities had strong deficits in the cortical and trabecular compartments of the distal radius compared to patients without vertebral deformities. We also observed that these deficits at the radius were particularly pronounced in patients with severe vertebral deformity. Thus, the bone microarchitecture at the distal radius seems to reflect vertebral fragility better than the bone architecture at the distal tibia. Yet, it is important to mention that in our study the overall peripheral bone microstructure was only assessed in patients with a T-score below -1.5 . Thus, the patients without vertebral deformities in this study were also in the range of osteopenia or osteoporosis regarding DXA T-score. There are only a few clinical studies that have compared patients with and without vertebral fractures in terms of peripheral changes in the trabecular and cortical compartments. These studies have reported conflicting results in differences observed only at the radius (31), or at the radius and tibia [31-33]. However, studies that reported similar differences at the radius and the tibia compared healthy control patients to osteopenic or osteoporotic patients with vertebral deformities 
[31, 34]. Furthermore, studies on patients with various kinds of fragility fractures support the notion that deterioration in bone microstructure plays an important role in the pathogenesis of fractures in general, and that such bone alterations are particularly pronounced at the distal radius $[35,36]$. This may be partially explained be the protective effect of weight-bearing on bone microstructure [8, 37]. Moreover, both primary and secondary hyperparathyroidism have been associated with a predominant deterioration of bone microstructure at the distal radius [38, 39]. The possibility that peripheral bone structure can predict the severity of vertebral fracture is of high clinical interest because severe fracture cases have a higher risk of developing changes in spine structure such as kyphotic deformities and spinal stenosis due to sagittal imbalance and degenerative changes. These degenerative alterations falsify aBMD measurement at the spine. Moreover, patients with spinal fusion and/or spinal degeneration in combination with hip joint replacement are not measureable with DXA. In these patients the assessment of the peripheral bone structure at the distal radius could be a useful tool to evaluate and monitor skeletal fragility.

Vitamin D plays an essential role in bone remodelling and is crucial for adequate uptake of calcium. Vitamin D deficiency has been identified as an important risk factor for stress fractures in several studies $[15,40]$. Correcting vitamin D deficiency can significantly increase bone mass in elderly people [41]. Nevertheless, a number of studies have reported high prevalence of deficient or inadequate vitamin $\mathrm{D}$ levels in patients requiring spinal surgery. Stoker et al. found that nearly $85 \%$ of adult patients undergoing spinal fusion showed deficient or inadequate 25-OH-D levels in the United States [20]. This is an even higher rate of insufficiency than in our study with $73.6 \%$ of patients showing inadequate vitamin $\mathrm{D}$ status. Other studies report similarly rates of vitamin D insufficiency comparable to the vitamin D status of the general population $[16,42]$.

Vitamin D deficiency often result in secondary hyperparathyroidism causing increased bone resorption. In our study $35.4 \%$ of patients showed elevated PTH levels. Some studies suggest that levels of $20 \mathrm{ng} / \mathrm{ml}$ are sufficient to avoid secondary hyperparathyroidism, while other studies argue for higher minimum threshold $(30 \mathrm{ng} / \mathrm{ml})$ to maintain skeletal health [43]. In our study, patients who received more than 1500-2000 I.E. vitamin D per day mostly reached levels of $25-\mathrm{OH}-\mathrm{D}>30 \mathrm{ng} / \mathrm{ml}$, while patients with lower intake (daily 1000 I.E.) showed levels between 20 and $30 \mathrm{ng} / \mathrm{ml}$. However, PTH did not differ between these groups suggesting that levels above $20 \mathrm{ng} / \mathrm{ml}$ are generally enough to avoid secondary hyperparathyroidism. Nevertheless, we think based on the current literature and own previous studies it is reasonable to recommend higher intake to reach 25OH-D levels above $30 \mathrm{ng} / \mathrm{ml}$ for optimal osteoid mineralization [43]. Most importantly, with proper treatment patients can have secondary hyperparathyroidism reversed in relatively short time before undergoing elective spinal surgery.

As gastric calcium solubility has been shown to be $\mathrm{pH}$-dependent, hypochlorhydria which is defined by reduced stomach acid production can induce calcium malabsorption which negatively affects bone mineralization [21]. Therefore, patients with hypochlorhydria which can be caused by long term use of proton pump inhibitors (PPI) display higher prevalence for osteoporosis and increased fracture risk [44]. As calcium gluconate or citrate have been shown to be very effective in correcting calcium malabsorption in patients with reduced stomach acid production [21], we recommend calcium gluconate or citrate supplementation in patients with permanent use of PPI.

Prevention is the most important principle in the management of osteoporosis. This is especially important for patient with previous fragility fractures. However, recent studies suggest that there is a large gap between patients with fragility fractures and those receiving appropriate anti-osteoporotic therapy [45]. While the availability of acute surgical treatment for vertebral fractures is considered excellent in Germany, many studies show a deficient in postoperative medical management of patients underlying low BMD resulting in high prevalence of untreated osteoporosis ranging from 30 to $70 \%[46,47]$. In our study, we found that $37.5 \%$ of patients had not received anti-osteoporotic treatment despite having an indication.

Our study has several limitations due to its retrospective design. Firstly, it has to be taken into account that the mean age in our study group was 70.1 years, an age where prevalence of osteoporosis is dramatically increasing. In fact the prevalence of osteoporosis in women $>70$ yearsold is $13-26 \%$ according to prior studies [48]. Secondly, compression fractures of the spine composed a large portion of patients which elevates the prevalence of osteoporosis and increases the number of patients in need of specific anti-osteoporotic therapy. Thirdly, regarding vitamin D status geographic differences has to be considered as northern European population generally has a higher risk to develop vitamin D deficiency and secondary hyperparathyroidism due to reduced sun light exposure.

\section{Conclusion}

This study shows that despite recent advances in the diagnosis and treatment of osteoporosis, elderly people scheduled for spinal surgery often show diminished bone mineral density, inadequate vitamin $\mathrm{D}$ status, elevated PTH levels and frequently have no anti-osteoporotic 
therapy. Future studies should aim to investigate the outcome of spinal surgery with regard to the preoperative bone mineral status and the effects of accurately timed preoperative anti-osteoporotic treatment. Considering the potential negative effects of low BMD and vitamin D deficiency for surgical outcome, preoperative screening and initiation of therapy for elderly patients is highly recommended.

\section{Abbreviations}

25-OH-D: 25-hydroxyvitamin D; ALP: Alkaline phosphatase; BAP: Bone specific alkaline phosphatase; BMD: Bone mineral density; DPD: Deoxypyridinoline; DXA: Dual-energy X-ray absorptiometry; HR-pQCT: High-resolution peripheral quantitative computed tomography; PTH: Parathyroid hormone; WHO: World Health Organization

\section{Acknowledgements}

Not applicable.

\section{Funding}

No funding was obtained for this study.

\section{Availability of data and materials}

The datasets used and analyzed during the current study are available from the corresponding author on reasonable request.

\section{Authors' contributions}

Study design: TS, JL, LP, RK, MA, FB, HM. Study conduct: TS, KE, TR, NO, JL, LP RK, HM. Data collection: TS, KE, TR, NO, HM. Data analysis: TS. Drafting manuscript: TS, KE, TR, HM. Approving final version of manuscript: TS, KE, TR, $N O, J L, L P, R K, M A, F B, H M$

\section{Ethics approval and consent to participate}

All research studies have been performed according to the rules of the local ethics committee of the University Medical Centre Hamburg-Eppendorf, Germany. All patient data were anonymized and evaluated in a retrospective design. The local ethics committee of the University Medical Center Hamburg-Eppendorf approved this retrospective study (PV5271). Written informed consent was obtained from participants for research studies and presented data.

\section{Consent for publication}

Not applicable.

\section{Competing interests}

T.S., K.E., T.R., N.O., J.L., R.K., L.P., M.A., F.B., H.M. declare that they have no conflict of interest. F.B. receives speaker and consultant fees from Alexion, Lilly, MSD, and Pfizer.

\section{Publisher's Note}

Springer Nature remains neutral with regard to jurisdictional claims in published maps and institutional affiliations.

\footnotetext{
Author details

'Department of Osteology and Biomechanics, University Medical Center Hamburg-Eppendorf, Lottestraße 59, 22529 Hamburg, Germany. ${ }^{2}$ Department of Orthopedic Surgery, University Medical Center Hamburg-Eppendorf, Martinistrasse 52, 20246 Hamburg, Germany. ${ }^{3}$ Clinic for Spinal Surgery, Schoen Klinik Eilbek, Denhaide 120, 22081 Hamburg, Germany.

Received: 3 October 2017 Accepted: 8 February 2018 Published online: 13 February 2018

References:

1. Reginster JY, Burlet N. Osteoporosis: a still increasing prevalence. Bone. 2006;38(2 Suppl 1):S4-9.

2. Melton $\sqcup$ 3rd, Chrischilles EA, Cooper C, Lane AW, Riggs BL. Perspective. How many women have osteoporosis? J Bone Miner Res. 1992;7(9):1005-10.
}

3. Cummings SR, Melton LJ. Epidemiology and outcomes of osteoporotic fractures. Lancet. 2002:359(9319):1761-7.

4. Lin JT, Lane JM. Nonmedical management of osteoporosis. Curr Opin Rheumatol. 2002:14(4):441-6.

5. Keller TS, Harrison DE, Colloca CJ, Harrison DD, Janik TJ. Prediction of osteoporotic spinal deformity. Spine (Phila Pa 1976). 2003;28(5):455-62.

6. Schuit SC, van der Klift M, Weel AE, de Laet CE, Burger H, Seeman E, Hofman A, Uitterlinden AG, van Leeuwen JP, Pols HA. Fracture incidence and association with bone mineral density in elderly men and women: the Rotterdam study. Bone. 2004;34(1):195-202.

7. Genant HK, Delmas PD, Chen P, Jiang Y, Eriksen EF, Dalsky GP, Marcus R, San Martin J. Severity of vertebral fracture reflects deterioration of bone microarchitecture. Osteoporos Int. 2007:18(1):69-76.

8. Stein EM, Liu XS, Nickolas TL, Cohen A, Thomas V, McMahon DJ, Zhang C, Yin PT, Cosman F, Nieves J, et al. Abnormal microarchitecture and reduced stiffness at the radius and tibia in postmenopausal women with fractures. J Bone Miner Res. 2010;25(12):2572-81.

9. Stein EM, Liu XS, Nickolas TL, Cohen A, McMahon DJ, Zhou B, Zhang C, Kamanda-Kosseh M, Cosman F, Nieves J, et al. Microarchitectural abnormalities are more severe in postmenopausal women with vertebral compared to nonvertebral fractures. J Clin Endocrinol Metab. 2012:97(10):E1918-26.

10. Klotzbuecher CM, Ross PD, Landsman PB, Abbott TA, 3rd, Berger M: Patients with prior fractures have an increased risk of future fractures: a summary of the literature and statistical synthesis. J Bone Miner Res 2000, 15(4):721-739.

11. Roux C, Fechtenbaum J, Kolta S, Briot K, Girard M. Mild prevalent and incident vertebral fractures are risk factors for new fractures. Osteoporos Int. 2007:18(12):1617-24

12. Geusens P, Chapurlat R, Schett G, Ghasem-Zadeh A, Seeman E, de Jong J, van den Bergh J. High-resolution in vivo imaging of bone and joints: a window to microarchitecture. Nat Rev Rheumatol. 2014:10(5):304-13.

13. Boutroy S, Van Rietbergen B, Sornay-Rendu E, Munoz F, Bouxsein ML, Delmas PD. Finite element analysis based on in vivo HR-pQCT images of the distal radius is associated with wrist fracture in postmenopausal women. J Bone Miner Res. 2008:23(3):392-9.

14. Melton $\sqcup$, 3rd, Riggs BL, van Lenthe GH, Achenbach SJ, Muller R, Bouxsein ML, Amin S, Atkinson EJ, Khosla S: Contribution of in vivo structural measurements and load/strength ratios to the determination of forearm fracture risk in postmenopausal women. J Bone Miner Res 2007, 22(9):1442-1448.

15. Chapuy MC, Arlot ME, Duboeuf F, Brun J, Crouzet B, Arnaud S, Delmas PD, Meunier PJ. Vitamin D3 and calcium to prevent hip fractures in the elderly women. N Engl J Med. 1992;327(23):1637-42.

16. Chapuy MC, Preziosi P, Maamer M, Arnaud S, Galan P, Hercberg S, Meunier PJ. Prevalence of vitamin $D$ insufficiency in an adult normal population. Osteoporos Int. 1997;7(5):439-43

17. Brown J, Sandmann A, Ignatius A, Amling M, Barvencik F. New perspectives on vitamin $D$ food fortification based on a modeling of $25(\mathrm{OH}) \mathrm{D}$ concentrations. Nutr J. 2013:12(1):151

18. Genant $H K$, Wu CY, van Kuijk C, Nevitt MC. Vertebral fracture assessment using a semiquantitative technique. J Bone Miner Res. 1993;8(9):1137-48.

19. Burt LA, Liang Z, Sajobi TT, Hanley DA, Boyd SK. Sex- and Site-Specific Normative Data Curves for HR-pQCT. J Bone Miner Res. 2016;31(11):2041-7.

20. Stoker GE, Buchowski JM, Bridwell KH, Lenke LG, Riew KD, Zebala LP. Preoperative vitamin D status of adults undergoing surgical spinal fusion. Spine (Phila Pa 1976). 2013;38(6):507-15.

21. Krause M, Keller J, Beil B, van Driel I, Zustin J, Barvencik F, Schinke T, Amling M. Calcium gluconate supplementation is effective to balance calcium homeostasis in patients with gastrectomy. Osteoporos Int. 2015;26(3):987-95.

22. Schinke T, Schilling AF, Baranowsky A, Seitz S, Marshall RP, Linn T, Blaeker M, Huebner AK, Schulz A, Simon R, et al. Impaired gastric acidification negatively affects calcium homeostasis and bone mass. Nat Med. 2009;15(6): 674-81.

23. Ponnusamy KE, Iyer S, Gupta G, Khanna AJ. Instrumentation of the osteoporotic spine: biomechanical and clinical considerations. Spine J. 2011;11(1):54-63.

24. Galbusera F, Volkheimer D, Reitmaier S, Berger-Roscher N, Kienle A, Wilke HJ. Pedicle screw loosening: a clinically relevant complication? Eur Spine J. 2015:24(5):1005-16.

25. Dodwad SM, Khan SN. Surgical stabilization of the spine in the osteoporotic patient The Orthopedic clinics of North America. 2013:44(2):243-9.

26. Lane JM, Nydick M. Osteoporosis: current modes of prevention and treatment. The Journal of the American Academy of Orthopaedic Surgeons. 1999; $7(1): 19-31$ 
27. Chin DK, Park JY, Yoon YS, Kuh SU, Jin BH, Kim KS, Cho YE. Prevalence of osteoporosis in patients requiring spine surgery: incidence and significance of osteoporosis in spine disease. Osteoporos Int. 2007;18(9):1219-24.

28. Pasco JA, Seeman E, Henry MJ, Merriman EN, Nicholson GC, Kotowicz MA. The population burden of fractures originates in women with osteopenia, not osteoporosis. Osteoporos Int. 2006;17(9):1404-9.

29. Szulc P, Boutroy S, Vilayphiou N, Chaitou A, Delmas PD, Chapurlat R. Cross sectional analysis of the association between fragility fractures and bone microarchitecture in older men: the STRAMBO study. J Bone Miner Res. 2011;26(6):1358-67.

30. Pasco JA, Henry MJ, Kotowicz MA, Sanders KM, Seeman E, Pasco JR, Schneider HG, Nicholson GC. Seasonal periodicity of serum vitamin D and parathyroid hormone, bone resorption, and fractures: the Geelong osteoporosis study. J Bone Miner Res. 2004;19(5):752-8.

31. Melton $\sqcup$ 3rd, Riggs BL, Keaveny TM, Achenbach SJ, Kopperdahl D, Camp J, Rouleau PA, Amin S, Atkinson EJ, Robb RA, et al. Relation of vertebral deformities to bone density, structure, and strength. J Bone Miner Res. 2010;25(9):1922-30.

32. Liu XS, Wang J, Zhou B, Stein E, Shi X, Adams M, Shane E, Guo XE. Fast trabecular bone strength predictions of HR-pQCT and individual trabeculae segmentation-based plate and rod finite element model discriminate postmenopausal vertebral fractures. J Bone Miner Res. 2013;28(7):1666-78.

33. Sornay-Rendu E, Cabrera-Bravo JL, Boutroy S, Munoz F, Delmas PD. Severity of vertebral fractures is associated with alterations of cortical architecture in postmenopausal women. J Bone Miner Res. 2009;24(4):737-43.

34. Wang J, Stein EM, Zhou B, Nishiyama KK, Yu YE, Shane E, Guo XE. Deterioration of trabecular plate-rod and cortical microarchitecture and reduced bone stiffness at distal radius and tibia in postmenopausal women with vertebral fractures. Bone. 2016;88:39-46.

35. Boutroy S, Bouxsein ML, Munoz F, Delmas PD. In vivo assessment of trabecular bone microarchitecture by high-resolution peripheral quantitative computed tomography. J Clin Endocrinol Metab. 2005;90(12):6508-15.

36. Stein EM, Kepley A, Walker M, Nickolas TL, Nishiyama K, Zhou B, Liu XS, McMahon DJ, Zhang C, Boutroy S, et al. Skeletal structure in postmenopausal women with osteopenia and fractures is characterized by abnormal trabecular plates and cortical thinning. J Bone Miner Res. 2014:29(5):1101-9.

37. Sornay-Rendu E, Boutroy S, Munoz F, Delmas PD. Alterations of cortical and trabecular architecture are associated with fractures in postmenopausal women, partially independent of decreased BMD measured by DXA: the OFELY study. J Bone Miner Res. 2007;22(3):425-33.

38. Trombetti A, Stoermann C, Chevalley T, Van Rietbergen B, Herrmann FR, Martin PY, Rizzoli R. Alterations of bone microstructure and strength in endstage renal failure. Osteoporos Int. 2013;24(5):1721-32.

39. Hansen S, Beck Jensen JE, Rasmussen L, Hauge EM, Brixen K. Effects on bone geometry, density, and microarchitecture in the distal radius but not the tibia in women with primary hyperparathyroidism: a case-control study using HR-pQCT. J Bone Miner Res. 2010;25(9):1941-7.

40. Burgi AA, Gorham ED, Garland CF, Mohr SB, Garland FC, Zeng K, Thompson K, Lappe JM. High serum 25-hydroxyvitamin D is associated with a low incidence of stress fractures. J Bone Miner Res. 2011;26(10):2371-7.

41. Grados F, Brazier M, Kamel S, Duver S, Heurtebize N, Maamer M, Mathieu M, Garabedian M, Sebert JL, Fardellone P. Effects on bone mineral density of calcium and vitamin D supplementation in elderly women with vitamin D deficiency. Joint Bone Spine. 2003;70(3):203-8.

42. Kim TH, Lee BH, Lee HM, Lee SH, Park JO, Kim HS, Kim SW, Moon SH, Prevalence of vitamin D deficiency in patients with lumbar spinal stenosis and its relationship with pain. Pain Physician. 2013;16(2):165-76.

43. Priemel M, von Domarus C, Klatte TO, Kessler S, Schlie J, Meier S, Proksch N, Pastor F, Netter C, Streichert T, et al. Bone mineralization defects and vitamin D deficiency: histomorphometric analysis of iliac crest bone biopsies and circulating 25-hydroxyvitamin D in 675 patients. J Bone Miner Res. 2010;25(2):305-12

44. Zhou B, Huang Y, Li H, Sun W, Liu J. Proton-pump inhibitors and risk of fractures: an update meta-analysis. Osteoporos Int. 2016;27(1):339-47.

45. Dipaola CP, Bible JE, Biswas D, Dipaola M, Grauer JN, Rechtine GR. Survey of spine surgeons on attitudes regarding osteoporosis and osteomalacia screening and treatment for fractures, fusion surgery, and pseudoarthrosis. Spine J. 2009;9(7):537-44

46. Freedman BA, Potter BK, Nesti $\amalg$, Giuliani JR, Hampton C, Kuklo TR. Osteoporosis and vertebral compression fractures-continued missed opportunities. Spine J. 2008;8(5):756-62.
47. Vestergaard P, Rejnmark L, Mosekilde L. Osteoporosis is markedly underdiagnosed: a nationwide study from Denmark. Osteoporos Int. 2005;16(2):134-41.

48. Looker AC, Melton LJ, 3rd, Borrud LG, Shepherd JA: Lumbar spine bone mineral density in US adults: demographic patterns and relationship with femur neck skeletal status. Osteoporos Int 2012, 23(4):1351-1360.

\section{Submit your next manuscript to BioMed Central and we will help you at every step:}

- We accept pre-submission inquiries

- Our selector tool helps you to find the most relevant journal

- We provide round the clock customer support

- Convenient online submission

- Thorough peer review

- Inclusion in PubMed and all major indexing services

- Maximum visibility for your research

Submit your manuscript at www.biomedcentral.com/submit
Biomed Central 